\title{
NOTA SOBRE LA FRUSTRADA REFORMA CONSTITUCIONAL ITALIANA DE 2006
}

\author{
MARC CARRILLO \\ Catedrático de Derecho Constitucional \\ Universidad Pompeu Fabra
}

\author{
SUMARIO.- \\ I. El estado actual de la reforma constitu- \\ cional del regionalismo italiano. \\ II. Consideraciones generales sobre la pre- \\ tendida reforma federal de 2006en Italia.
}

\section{EL ESTADO ACTUAL DE LA REFORMA CONSTITUCIONAL DEL REGIONALISMO ITALIANO}

La pretendida reforma federal impulsada durante las XIV Legislatura del Parlamento italiano por el fenecido gobierno Berlusconi, topó con el rechazo expresado por el cuerpo electoral en el referéndum celebrado los días 25 y 26 de junio de 2006. En realidad, dicho proyecto de reforma constitucional tenía muy poco sentido federal a pesar de haber sido calificada así por la mayoría política que lo promovió. Los ejes de la misma fueron una limitada transferencia de nuevas competencias a las Regiones, la modificación del Senado y una sensible revisión de la posición institucional del Primer Ministro, hasta el punto de suscitar en el seno de la doctrina iuspublicista italiana la convicción de que, en realidad, con la reforma se estaba introduciendo un cambio en la forma de gobierno.

Esta frustrada reforma constitucional pretendía proyectarse sobre otras ya concluidas del regionalismo italiano y llevadas a cabo durante la XIII Legislatura (1996-2001) por los gobiernos de centro-izquierda a través de tres leyes constitucionales. La primera, la Ley 1/1999 que estableció un nuevo marco para la autonomía política y la forma de gobierno en las Regiones de régimen ordinario; la segunda, la Ley 2/2003, que configuró también una nueva regulación para la autonomía de las Regiones de régimen especial: Sicilia, Cerdeña, Valle 
de Aosta, Trentino-Alto Adigio y Friuli-Venezia Giulia. Y, finalmente, la tercera es la Ley 3/2001 que ha complementado las previsiones de la Ley 1/2001, relativas a la reforma del Título V de la Constitución.

De este conjunto de reformas constitucionales ya consolidadas cabe destacar sobre todo la modificación de las reglas que establecen el nuevo sistema de reparto de competencias entre el Estado y las Regiones. Como es sabido, la configuración constitucional de las regiones de acuerdo con la redacción dada a la Constitución en 1947 fue la propia de los Estados políticamente descentralizados acordes con el modelo regional. Esto es, el Estado dispone de unas competencias generales que son especificadas en la Constitución y, asimismo, las Regiones disponen de las suyas que también son enumeradas en la norma suprema. El gran cambio que las reformas de 2001 han producido, consiste en el establecimiento de un sistema de delimitación de las competencias que es propio de la técnica federal. Pero esta innovación ha afectado también a la propia naturaleza del Estatuto regional como norma reguladora de la autonomía política ${ }^{1}$.

\section{a) Acerca de la naturaleza del Estatuto regional}

En efecto, en lo que concierne a los estatutos de las Regiones de régimen ordinario, la reforma constitucional ha generado cambios formales y materiales. Formalmente, el estatuto regional ha pasado a ser aprobado por ley regional cuando con anterioridad lo era mediante ley estatal. Y desde un punto de vista material, su contenido ha variado con la introducción en algunos Estatutos de un capítulo de derechos y además, en el ámbito de la autonomía institucional, se han incorporado órganos internos de control estatutario, o lo que en la terminología italiana se ha dado en denominar colegios de garantía estatutaria.

El artículo 123 de la Constitución, en su primer apartado, establece ahora que "cada Región tendrá un Estatuto que determine, de acuerdo con la Constitución, su forma de gobierno y sus principios fundamentales de organización y funcionamiento..... En su apartado segundo precisa que "el Estatuto será aprobado y modificado por el Consejo regional mediante ley votada favorablemente por mayoria absoluta de sus componentes, en dos lecturas sucesivas con intervalo no inferior a dos meses, y para la cual no será necesario el visto bueno del Comisario del Gobierno".

Luego, el Estatuto es una norma jurídica cuya aprobación corresponde exclusivamente al Consejo regional, el órgano legislativo de la Región. La lógica federal aparece aquí de forma explícita, en la medida que el Parlamento de la República no interviene como antes en la aprobación del Estatuto, que ahora queda a disposición de los parlamentarios regionales para que éstos determi-

1 LUCIANI, M.: "Le nuove competenze legislative delle Región a statuto ordinario. Prime osservazioni sui prncipali nodi problematici della legge constituzionale del 2001", en: Il lavoro nelle pubbliche administrazioni, 2002. 
nen los principios fundamentales y la forma de gobierno de la Región. Por supuesto, de forma incondicionada sino acorde con la Constitución, norma suprema del Estado de la que derivan todos los Estatutos regionales. Se trata, por tanto, de un acto normativo de la Región que aún siendo una ley formal no puede equiparse a cualquier otra que apruebe el Consejo regional. No es una ley regional más. Y no lo es porque tanto en razón a su contenido, como a su procedimiento de aprobación las diferencias con la ley ordinaria regional son evidentes. Por lo que concierne al contenido, la Constitución prescribe que el Estatuto ha determinar los principios generales y la forma de gobierno regional, es decir los aspectos de orden organizativo e institucional. En cuanto al procedimiento de aprobación, éste es de carácter especial puesto que se exigen dos votaciones sucesivas favorables por mayoría absoluta de los miembros del Consejo Regional, que habrán de producirse en un intervalo no superior a dos meses. Y, además, se establece un referéndum optativo para su aprobación definitiva por el electorado de la Región, "si dentro de los tres meses siguientes a su publicación así lo pidiere la quinta parte de los electores de la Región o un quinto de los componentes del Consejo Regional.. En ese caso, el Estatuto deberá ser aprobado por la mayoría de los votos válidamente emitidos.

No parecen haber dudas razonables de que el Estatuto no es asimilable a una ley ordinaria de la Región y que se trata de una ley regional especial y siempre subordinada a la Constitución. En los mismos términos se expresa la Corte Constitucional cuando al referirse a los Estatutos de régimen ordinario los considera como leyes regionales peculiares o especiales (Sentencias 2 y 304/2002). Como subraya ORTEGA SANTIAGO invocando la jurisprudencia constitucional italiana al respecto (sentencias 372, 378 y 379/2004) el Estatuto regional es una fuente del sub-ordenamiento jurídico regional dotada de un ámbito reservado y especializado de competencias, de tal manera que su control de constitucionalidad no puede ser el de carácter sucesivo que afecta a todas la leyes ordinarias de la Región, sino que ha de ser preventivo a fin de evitar que una eventual inconstitucionalidad pueda arrastrar a las leyes regionales subordinada al Estatuto. Aunque lo que de forma más precisa establece la reforma constitucional al respecto, es que dentro del plazo de los treinta días siguientes a la publicación del Estatuto el Gobierno de la República podrá plantear ante la Corte Constitucional la cuestión de inconstitucionalidad si duda de la constitucionalidad de su contenido. Por tanto, el Estatuto regional es una norma jurídica que ocupa una posición primaria y fundamental en el ordenamiento regional (sentencia 12/2006) que como tal opera también como parámetro de enjuiciamiento jurídico para las leyes regionales a fin de evaluar su adecuación a la Constitución ${ }^{2}$.

2 ORTEGA SANTIAGO, C.: "Los nuevos Estatutos de Autonomía de las regiones italianas". $R e$ vista Española de Derecho Constitucional, n. ${ }^{\circ}$ 78, septiembre-diciembre, Madrid, 2006, pp. 43-61. 


\section{b) La incorporación de un capítulo de principios y derechos en los Estatutos}

Este apartado constituye otra de las novedades derivadas de la reformas constitucionales de la XIII Legislatura, aunque como ha se ha señalado, en los estatutos de 1971 ya se contenían normas programáticas en este sentido. En ls Estatutos actuales destacan las previsiones normativas que establecen remisiones a textos internacionales en materia de derechos y libertades. Asimismo, también se prevén normas relativas a derechos de participación política, derechos del ámbito social y derechos de la llamada tercera generación, en especial los relacionados con la bioética.

La posición de la Corte Constitucional al respecto de los dos casos en los que se ha pronunciado (en los Estatutos de la Toscana, Umbria y de la Emilia Romagna) no deja de ser singular, puesto que para la jurisdicción constitucional italiana, estas previsiones estatutarias sobre el derecho de sufragio de los inmigrantes y las formas de convivencia distintas del matrimonio, son meras declaraciones de intenciones sobre de políticas públicas a llevar a cabo por las citadas Regiones, carentes de valor jurídico alguno ni siquiera de carácter programático (Sentencia 372, 378 y 379/2004). Sin embargo, cabe preguntarse cual habrá de ser la posición de la Corte en el supuesto de que una ley regional que desarrolle las previsiones estatutarias en estas u otras materias suponga una eventual infracción de relevancia constitucional. Pues no ha de parecer ilógico que en ese hipotético supuesto, la Corte deberá entrar a enjuiciar el caso y se hace difícil pensar que ello no sea así. Por lo que seguramente, concluir a prio$r i$ en que no cabe no atribuir ningún valor jurídico a las previsiones establecidas en los Estatutos regionales en materia de derechos, trasluce una posición extrema que se compadece mal con el carácter de ley especial o singular que la propia Corte italiana ha atribuido a los Estatutos de las Regiones ${ }^{3}$.

\section{c) La modificación del sistema de distribución de competencias}

En efecto, ahora la Constitución establece en su artículo 117, primer apartado, que el poder legislativo será ejercido por el Estado y las Regiones, a través de un sistema de distribución de competencias que el citado artículo 117 en su apartado segundo, detalla las materias respecto de las cuales el Estado dispondrá de la facultad exclusiva de legislar. En su apartado tercero precisa las materias que serán objeto de legislación concurrente entre el Estado y las Regiones, en cuyo ámbito funcional, las Regiones disponen de potestad legislativa,

3 CASTELLÀ ANDREU, J. M. a : «El reconocimiento y garantía de los derechos y libertades en los Estados compuestos. Una aproximación comparada", en Derechos y libertades en los Estados compuestos (M.A. APARICIO, ed.). Atelier. Barcelona, 2005, pp. 11-38.

ROSSI, Emanuele: "Derechos de libertad y Estatutos regionales. La situación italiana", en : Derechos y libertades en los Estados compuestos (M.A. APARICIO, ed.). Atelier. Barcelona, 2005, pp. 201-234. 
excepto en lo que concierne a la determinación por el Estado de los principios fundamentales de dicha legislación (es decir, seguramente lo que el contexto constitucional español se correspondería con la legislación básica estatal). Finalmente, y acorde con este enfoque de corte federal que inspira la reforma constitucional, el apartado quinto del artículo 117 establece que corresponde a las Regiones la potestad legislativa en cualquier materia no expresamente reservada a la legislación del Estado.

Dicho lo cual, no obstante, hay que precisar de inmediato que la reforma no se ajusta al modelo federal en sus contornos más clásicos basados en la igualdad entre los entes subestatales, puesto que tras las reformas citadas se sigue manteniendo la distinción entre las Regiones de régimen especial y las de régimen ordinario, aunque se arbitren vías para una eventual igualación.

La potestad reglamentaria corresponde al Estado en las materias que son de su exclusiva competencia legislativa, si bien está previsto que incluso en estos casos puedan delegarlas a las Regiones. En las otras materias donde la competencia es compartida con el Estado o bien corresponde enteramente a las Regiones, son éstas las que ejercen la potestad reglamentaria. Asimismo, los $\mathrm{Mu}-$ nicipios, las Provincias y las Urbes metropolitanas disponen de potestad reglamentaria para regular la organización y el desarrollo de las funciones que les están encomendadas (apartado 7, del artículo 117).

Siguiendo la estela que ha ido dejando el Derecho Comunitario, la reforma constitucional también se ha hecho eco en el sistema de distribución de competencias, del principio de subsidiariedad en la gestión de los asuntos públicos por la administración más próxima al ciudadano, ya sea en las relaciones entre las diversas administraciones públicas como entre éstas y los propios ciudadanos. Así, en relación a las primeras, el apartado primero del artículo 118 establece que "se asignan a los Municipios las funciones administrativas, a menos que, para asegurar su ejercicio unitario, se encomienden a las Provincias, Urbes metropolitanas, Regiones y al Estado en virtud de los principios de subsidiariedad, de diferenciación y de adecuación". Y con respecto a las segundas, en el apartado quinto del mismo precepto se establece que "el Estado, las Regiones, las Urbes metropolitanas, las provincias y Municipios fomentarán la iniciativa autónoma de los ciudadanos, individualmente o asociados, para el desarrollo de actividades de interés general, conforme al principio de subsidiariedad $"{ }^{4}$.

\section{d) Los órganos regionales de garantía estatutaria}

La aprobación de los Estatutos en las Regiones de régimen ordinario mediante la ley regional, sin intervención de la ley estatal no excluye, por supuesto, del control de constitucionalidad de dichos Estatutos y de las leyes re-

4 D'ATENA, A.: “Materia legislative e tipologia delle competenze", Quaderni costituzionali, Anno XXIII, n.1, marzo 2003, pp. 15-23. 
gionales por la Corte Constitucional. Es del todo evidente que el monopolio del control de constitucionalidad de las leyes corresponde a la Corte Constitucional. No obstante, en el seno de la doctrina italiana se ha planteado la cuestión del control de las leyes regionales cuando éstas, sin ser abiertamente contrarias a la Constitución sí lo sean al Estatuto. En ese caso, se ha llegado a considerar que el control ejercido por la Corte pudiese llegar a devenir insuficiente. Y ésta ha sido el motivo que ha legitimado la incorporación al elenco institucional de las regiones, de los órganos de garantía estatutaria.

En principio, no hay razón suficiente para cuestionar la constitucionalidad de las nuevas previsiones estatutarias de una buena parte de las Regiones italianas de incorporar a su organización institucional, los llamados colegios de garantía estatutaria. Se trata de unos órganos de naturaleza no jurisdiccional y de perfil y carácter consultivo que están encargados de velar por la adecuación de la ley regional al Estatuto. Su constitucionalidad no ha de ofrecer reparos, en la medida en que su existencia obedece a la configuración de un autocontrol interno de carácter previo sobre proyectos de normas regionales en su procedimiento interno de aprobación. Lo que en nada empece a la Corte Constitucional, en caso de ser requerida para ello por las instancias legitimadas, para que lleve a cabo su función jurisdiccional —ésta sí- de carácter vinculante para todos los poderes públicos.

Entre otras, dos son las Regiones que ofrecen ejemplos de control previo por parte de este tipo de órganos, que pueden suscitar una mayor controversia acerca de la naturaleza de su función fiscalizadora sobre la adecuación al respectivo Estatuto de la ley regional. Especialmente, a causa del carácter vinculante atribuido al dictamen emitido por el órgano de garantía y su eventual influencia sobre el ejercicio de la potestad legislativa del Consejo Regional. Éste es el caso de los Estatutos de las Regiones de Calabria y Abruzzo. En el primer supuesto, el juicio de adecuación al Estatuto de un proyecto legislativo tiene carácter vinculante pero éste desaparece si el Consejo Regional reitera el contenido de su decisión normativa por mayoría absoluta de sus miembros. En el segundo, el dictamen se ejerce no sobre un proyecto sino en relación a textos legislativos que ya han sido aprobados pero pendientes de promulgación y publicación.

La Corte Constitucional italiana, en su sentencia 12/2006 ha venido a avalar la constitucionalidad de la existencia de los Colegios Regionales para las Garantía Estatutarias, entendiendo que: $1 .^{\circ}$ ) no existe una limitación del potestad legislativa del Consejo Regional sino una agravación del procedimiento de aprobación, a través del establecimiento de este control interno en el ámbito de la Región; $2^{\circ}$ ) dicho control es una forma de incidir no en el contenido de la ley sino en la deliberación sobre la misma por parte del órgano legislativo regional. Cabe preguntarse, sin embargo, que ocurriría si mediante el dictamen del órgano consultivo la ley debiese ser modificada por el Consejo Regional. Ciertamente, constituye una limitación del ejercicio de su potestad legislativa, pero ello es una previsión de autocontrol que en el marco de la autonomía institucional ha adoptado la Región y sin que, en ningún caso, impida que el re- 
sultado derivado del dictamen, una vez cristalizado en ley, ésta pueda ser enjuiciada por la Corte Constitucional5.

\section{e) La supresión del control por el Estado de los actos regionales}

Una de las características más señeras del regionalismo italiano fundado con la Constitución que entra en vigor en 1948 fue, sin duda, el control por el Estado de los actos de las Regiones. Un control que afectaba a los Estatutos, las leyes, los reglamentos y en general a todos los actos administrativos, no sólo por razones de constitucionalidad o legalidad sino también -y aquí es donde residía una de las limitaciones más decisivas de este regionalismo- de oportunidad, en función de su eventual incidencia en el ámbito de los intereses nacionales.

Las reformas de la XIII Legislatura han suprimido esta gravosa limitación a la autonomía política de las Regiones. Como hemos visto con anterioridad, los Estatutos de las regiones de régimen ordinario no son objeto de aprobación por el Estado sino por el Consejo Regional de la Región. El Gobierno ya no controla los vicios de legitimidad de los actos regionales sino que ello ya compete a los tribunales. Sin embargo, y como se reseñará más adelante, la reforma de 2004 ha vuelto a reinstaurar el control estatal de oportunidad por razones de interés nacional.

\section{f) La posición del Senado}

La tendencia federalizante de algunas de las reformas constitucionales no se trasladó al Senado. En efecto, al mantenerse la distinción entre Regiones de regímenes especial y ordinario, se hacía difícil configurar una Cámara alta basada en los cánones clásicos del modelo federal. La reforma de la XIII Legislatura ha consistido en la constitución de una Comisión bilateral Senado-Cámara de Diputados integrada por veinte miembros, a fin de procurar una participación consultiva de las Regiones y también de los entes locales en el proceso legislativo, cuando los proyectos legislativos afecten a cuestiones regionales. Con este objetivo, la Comisión ha de ser preceptivamente consultada cuando el Parlamento apruebe una ley-marco o una ley relativa a aspectos de la financiación regional. Si bien la posición de la Comisión no tiene carácter decisorio o vinculante para el Parlamento, la reforma establece que en caso de que éste no apruebe el criterio sostenido por la Comisión, lo deberá hacer en reunión plenaria y por mayoría absoluta. 


\section{g) El mantenimiento de la distinción entre Regiones de régimen especial $y$ ordinario}

La reforma con pretensiones de adecuarse a una cierta lógica federal no ha alcanzado a la supresión de la distinción entre Regiones de régimen especial y las de régimen ordinario. La única opción en este sentido es las posibilidad contemplada en el apartado 3 del artículo 116, según la cual, las Regiones de régimen ordinario podrán acceder a modalidades y condiciones especiales de autonomía en materias de competencia compartida entre Estado y las regiones especiales previstas en el artículo 117.3. y en materias relativas a jurisdicción y normas de procedimiento para la justicia de paz; enseñanza y también medio ambiente. La asunción de estas competencias deberá hacer mediante ley estatal aprobada por mayoría absoluta, a iniciativa de la región interesada, oídas las entidades locales y de acuerdo con los principios constitucionales del artículo 119 (relativos a la autonomía financiera de los Municipios, Provincias, Urbes Metropolitanas y Regiones). La base de esta ley se fundamentará en un acuerdo entre el Estado y la Región interesada.

En cuanto a las Regiones de régimen ordinario la reforma constitucional de 1999 estableció la opción de escoger una forma de gobierno basada en la elección directa del Presidente de la Región y la forma parlamentaria de gobierno, a través de la elección parlamentaria. Los Estatutos de estas Regiones son aprobados por ley regional que se limita a regular los aspectos organizativos de la Región, a diferencia de las de régimen especial, que al regular también sus competencias que asumen son aprobadas por ley estatal.

\section{h) La participación de las Regiones en los asuntos internacionales y en los actos de la Unión Europea}

Este ha sido uno de los temas más recurrentes en los últimos años del proceso de institucionalización de la Unión Europea. Especialmente, las Regiones que son titulares de potestad legislativa propia en los diversos Estados compuestos que forman parte de la Unión, han ejercido un papel de lobby en pro de su participación en la configuración de la voluntad de sus respectivos ante las instituciones europeas, como así lo expresó el Informe Lamassoure. La reforma constitucional italiana, de acuerdo con lo establecido en el apartado 6 del artículo 117 se ha hecho eco de ello en los siguientes términos:

- En las materias que son de su competencia (sin que la Constitución distinga en razón a la naturaleza de aquéllas) tanto las Regiones como las Provincias autónomas de Trento y Bolzano disponen de la potestad de participación y de ejecución de las decisiones de los entes supraestatales en el sentido que sigue:

- Participar en las decisiones destinadas a la formación de los actos normativos omunitarios. 
- Proveer la aplicación y el cumplimiento de los acuerdos internacionales y de los actos de la Unión Europea.

- Las normas de procedimiento de esta participación en asuntos internacionales y europeos son las que establece el Estado las cuales, en su caso han de prever los supuestos de sustitución estatal en caso de incumplimiento por parte de la Región.

\section{CONSIDERACIONES GENERALES SOBRE LA PRETENDIDA REFORMA FEDERAL DE 2006 EN ITALIA}

La reforma de la Constitución italiana presentada por el Gobierno Berlusconi en 2004 para establecer un sistema federal en el país transalpino y que objeto de un prolongado debate en el Parlamento de Roma, fue rechazada en el referéndum de 25 y 26 de junio de 2006.

Con independencia de este hecho, esta importante Ley Constitucional de la XIV Legislatura de la República italiana ofreció especial interés, sobre todo, por el diseño federal que parcialmente pretendía introducir en la Constitución promulgada el 1 de enero de 1948, y que tras las leyes constitucionales de 1999 y 2001 ha experimentado un cambio notable en la regulación del constitucionalismo regional italiano.

La Constitución de 1947 fue una norma concebida para institucionalizar un Estado regional, que reconocía autonomía política a las regiones, pero que no se institucionalizó inmediatamente, pues con la excepción de cuatro de las cinco regiones a las que la Constitución reconocía un régimen especial (Sicilia, Cerdeña, el Valle de Aosta y el Trentino Alto Adagio) que se constituyeron entre 1946 y 1948, el resto lo hicieron mucho más tarde. Éste fue el caso de la quinta de régimen especial, el Friuli-Venecia Julia, que no lo hizo hasta 1963, una vez solventadas las controversias territoriales con Yugoslavia, por la cuestión de la ciudad de Trieste y de las quince restantes de régimen común, que tuvieron que esperar a la Ley constitucional de 1968, que reguló la elección de los Consejos Regionales (Parlamento regional) y a la Ley de 1970, referida a la cuestión, siempre esencial, de la hacienda y a la autonomía financiera.

La reforma constitucional que en 2004 se pretendía llevar a cabo por el Gobierno de centro derecha, frente a las reformas ya asentadas de los Ejecutivos de centro-izquierda de Prodi, d'Alema y Amato (1999-2001), suponía un paso más en la línea de estructurar la República italiana conforme a criterios de carácter federal, aunque ciertamente su alcance no significaba que, de haberse aprobado en referéndum, Italia se hubiese convertido en un modelo clásico de Estado Federal. Si bien es cierto que introducía cambios institucionales en relación a la posición institucional del Senado y se acrecentaban ligeramente las competencias de las Regiones, la reforma no alcanzaba a otras instituciones como es el caso, por ejemplo, del Poder Judicial, que seguía siendo único para toda la República. 
Como se ha expuesto anteriormente, los proyectos de reforma federal datan de los últimos ocho años. En el programa del Gobierno Berlusconi se han caracterizado por su osadía en el ámbito tributario, un objetivo prioritario de la Liga Norte de Bossi, el que otrora fuera singular Ministro de la coalición de gobierno de centro derecha, encargado de la reforma institucional y la devolución, como así se denomina el Ministerio a su cargo.

a) El primer pilar de la reforma venía referido a la organización institucional de la Cámara alta. En efecto, el Senado, que pasaba a denominarse Senado federal de la República, veía reducida su composición a 252 senadores electivos, (en la actualidad son 315 electivos, más los natos y los vitalicios que se mantienen), que eran elegidos sobre la base regional y simultáneamente a la elección de los respectivos Consejos Regionales, que son las asambleas legislativas regionales. La representación de cada región en la Cámara alta se establece con criterio de proporcionalidad acorde con su población, lo que le diferencia del modelo federal clásico (por ejemplo, los Estados Unidos), en el que los territorios disponen de idéntica representación sea cual fuere la población que los integre.

Merece especial mención la previsión que establecía la reforma según la cual los representantes de las entidades locales también participaban en las funciones del Senado, aunque sin derecho de voto, de tal manera que, en cierta forma, ésta deviene una Cámara de representación territorial en el sentido más amplio del término. Por lo que se refiere a las funciones que le estaban atribuidas al Senado, la reforma modificaba el iter legislativo para la aprobación de las leyes, de tal manera que en las materias que forman parte del amplio catálogo de las competencias compartidas entre el Estado y las Regiones (por ejemplo, el comercio exterior, algunos aspectos de la educación, protección de la salud, la ordenación de las comunicaciones, etc.) prevalecía la decisión del Senado en caso de discrepancia con la Cámara de Diputados. Pero este criterio quedaba invertido en favor de la Cámara baja, en los supuestos de competencias exclusivas de Estado. Por otra parte, en lo que concernía a la función de control al Gobierno, el cambio que propone la reforma es sustancial, puesto que el Ejecutivo italiano ya no tendrá que disponer de la confianza parlamentaria del Senado, ya que ésta queda reservada en exclusiva a la Cámara de Diputados. Una previsión que resultaba lógico que fuese así, puesto que el Senado federal es de extracción regional y con un mandato legislativo para los senadores que lo componen que depende sólo de las elecciones en las asambleas legislativas regionales y no es tributario de la elección del cuerpo electoral de toda la República. Así, pues, la Cámara de Diputados representa a los ciudadanos de la República, mientras que el Senado asume la de los ciudadanos de las Regiones. Ambas representaciones son plenamente compatibles en la medida que las dos expresan la soberanía popular.

En otro orden de cosas, con esta nueva institucionalización, el Senado nombraba a cuatro de los quince jueces que integran la Corte Constitucional, lo 
cual había de permitir una mayor participación de las Regiones en las instituciones centrales del Estado italiano.

b) La organización de las competencias constituye el segundo pilar de la reforma constitucional. Las regiones veían moderadamente aumentado su poder de autogobierno, al disponer ahora de competencia exclusiva en materias como la asistencia y organización sanitaria; la organización de la enseñanza escolar, la gestión de los institutos de enseñanza y la definición de la parte de los programas escolares y formativos de interés específico para la región, así como la competencia sobre la policía administrativa regional y local. No obstante, la reforma precisaba el alcance de las competencias exclusivas del Estado concretando su contenido, mereciendo aquí una especial referencia las relativas a: la promoción internacional del sistema económico y productivo nacional; la política monetaria; la tutela del crédito; la organización común del mercado; las normas generales (el equivalente a la legislación básica española) sobre la tutela de la salud, la seguridad y la calidad alimenticia, la seguridad en el trabajo; la ordenación de la producción estratégica, el transporte y la distribución nacional de la energía, etc. Y para conseguir una más eficaz articulación de estas y otras competencias, la reforma constitucionalizaba algunos instrumentos de colaboración, como es el caso de la Conferencia Estado-Regiones, para llevar a cabo una colaboración leal entre los diversos entes territoriales y promover acuerdos. Asimismo, garantizaba expresamente la autonomía de los entes locales, en el marco que a la par establezcan tanto la ley estatal como la ley regional, lo que pone de manifiesto la doble dependencia - o el carácter bifronte, en la terminología empleada en España por el Tribunal Constitucional- de los municipios y otros entes locales para delimitar la autonomía de la disponen.

Sin embargo, esta revisión constitucional recuperaba un poder de control político del Estado sobre la ley regional. En efecto, cuando el Gobierno considere que una ley regional perjudica el interés general de la República, y habiendo requerido a la región para que la modifique, en caso de rechazo, podrá instar al Parlamento para que por mayoría absoluta anule la ley. Nótese, pues, que no se trata de un control jurisdiccional como el establecido por las reformas constitucionales de la XIII Legislatura a cargo de la Corte Constitucional, y como es el caso previsto en la Constitución española, sino de un control de oportunidad, lo que hace que este sui generis modelo federal italiano proporcionase al Estado una exorbitante preeminencia sobre las regiones.

c) La reforma se muestra especialmente sensible al carácter plurilingüe de la República, y con este fin establece que en las regiones de Estatuto especial y en las provincias autónomas de Trento y Bolzano sea reconocida la paridad de derechos a los ciudadanos, sea cual fuere el grupo lingüístico al que pertenezcan, lo cual, lógicamente, habrá de redundar en beneficio de una equiparación de derechos y deberes al respecto.

d) En la cuestión decisiva: la financiación, el proyecto de reforma fue más bien parco. Los criterios se habían de establecer en una ley estatal, la cual debía de asegurar la transferencia de bienes y recursos para las Regiones, que asegurase el pleno ejercicio de las competencias en un plazo de cinco años. Y 
en cuanto al federalismo fiscal y su relación con la hacienda estatal, se prescribía que en ningún caso la autonomía impositiva de las Regiones y de los entes locales podía determinar un incremento general de la presión fiscal.

e) Pero los cambios introducidos por la reforma constitucional de 2004 no se limitaban a lo expuesto. También y, sobre todo, afectaban a la forma de gobierno, el tema que de hecho - y a juicio de una buena parte de la doctrina italiana - constituía el verdadero objeto de la reforma constitucional del gobierno de centro-derecha. Una forma de gobierno que, ciertamente, veía modificada su estructura a favor de una posición más preeminente del Primer Ministro. Porque, en efecto, en la nueva redacción que se proponía del artículo 94 de la Constitución para regular las relaciones entre el Gobierno y el Parlamento, y en especial de la moción de censura, se establecía que:

- El Primer Ministro debe dimitir si una moción de censura es aprobada por la mayoría absoluta de los miembros de la Cámara de Diputados.

- El Primer Ministro también dimite aún cuando a pesar de que la moción de censura no haya prosperado, ésta haya sido rechazada con el voto determinante de diputados que no pertenezcan a la mayoría de aquéllos otros que con anterioridad habían investido al Primer Ministro.

Sin duda, éste último supuesto es el que supone una decisiva innovación en el esquema clásico de las relaciones entre el Parlamento y el Gobierno en la forma de gobierno parlamentaria. Porque el sentido de esta reforma constitucional de 2004 no era otro que vincular la mayoría parlamentaria de investidura al Primer Ministro durante todo su mandato ejecutivo. Es decir, la mayoría que lo había elegido. La consecuencia de esta nueva regla reguladora de las relaciones entre la Cámara de Diputados (el Senado ya no intervenía en el control político del Ejecutivo) y el Gobierno, suponía que el primer Ministro, llegado el caso de una crisis ministerial, no podría disponer de una mayoría alternativa para seguir gobernando si la anterior - aquélla que le otorgó la investidura para Gobernar - le retiraba la confianza. Es decir, si otra mayoría resultaba determinante para impedir que una censura prosperase y así seguir gobernando con nuevos socios, a pesar de ello el Primer Ministro debía dimitir igualmente. Con lo cual, la reforma producía el efecto perverso de ligar indirectamente y de manera férrea al Primer Ministro a la mayoría parlamentaria de la investidura, como si de un contrato administrativo de adhesión se tratase, sin dejar margen para un eventual cambio de criterio, en función de la acción de gobierno registrada durante de legislatura. Porque, de hecho, esta dimisión del Primer Ministro aún cuando la censura no haya prosperado, a causa del apoyo de otra mayoría parlamentaria, conduce a la mayoría que le otorgó la investidura a escoger entre dos alternativas extremas: una, mantener al Primer Ministro y a su Gobierno en una especie de relación simbiótica a pesar del desacuerdo constatado, si se quiere seguir formando parte de la mayoría de gobierno; y la otra, impedir que siga gobernando a pesar de que haya podido reconstruir una nueva mayoría para hacerlo. 
f) En otro orden de las innovaciones de esta nonata reforma constitucional cabe destacar las siguientes:

1) La supresión de la Iniciativa legislativa popular, en un país en el que, junto al referéndum abrogativo, los instrumentos de democracia semidirecta ha sido unos de los referentes del sistema político (artículo 71).

2) Otra singularidad fue la constitucionalización de las Administraciones independientes, para el desarrollo de la actividad y la garantía de los derechos y libertades reconocidos en la Constitución (artículo 88-bis). La forma jurídica de estos entes de control en diversos ámbitos de la Administración pública ha sido la propia de las llamadas autoridades administrativas independientes, dotadas de autonomía orgánica y funcional. Una modalidad del Derecho Público que opera en otros sectores como el de la protección de datos personales, el mercado de valores o el sector energético. Son creadas por ley como administraciones singulares, independientes de los poderes del Estado y relacionadas con el Gobierno en virtud de un principio de competencia pero de no jerarquía. Sus decisiones, incluida la potestad reglamentaria derivada de la que gozan, están sometidas, claro está, al control judicial.

3) La defensa de la autonomía local frente a leyes del Estado o de las Regiones se instrumenta a través del establecimiento de una cuestión de legitimidad constitucional ante la Corte, cuya regulación se remite a una ley constitucional (artículo 127) ${ }^{6}$.

La XV Legislatura del actual Gobierno de la amplia y heterogénea coalición encabezado por Romano Prodi en el momento de redactar estas notas en abril de 2007, deberá sentar las bases de las cuestiones que complementen las reformas ya consolidadas y la revisión de las que han quedado pendientes tras el rechazo del referéndum de 2006.

ABSTRACT. The constitutional reform of the Italian regional system began with the constitutional Laws during the XIII Legislature, under governments of center-left (1999-2001). These reforms has meant a change in the legal nature of the regional Statues; they have incorporated new contents in the Statues, as it is the case of the chapters that regulate the beginnings and laws and the regional organs of statutory guarantee; they have meant a modification of the system of distribution of competences, in a logic that is nearer to the federal model; they have suppressed the control of opportunity for the State of the

6 CARETTI, P.: «Una seconda reforma peggiore della prima: note critiche Della reforma del Titolo V della Costituzione", Le Regione, 2004.

RUGGERI, A.: "Reforma del titolo V, procedimento legislativo regionale e teoria delle fonti", in Rassegna parlamentaria, 2004. 
arrangements and acts of the Regions, have maintained the distinction between regions of special and ordinary regime and, have regulated the regional participation in the international and European matters. In front of this schema strengthened of constitutional reform, the new modification of the Constitution carried out from 2004 by the Government of center-right presided over by Berlusconi introduced important changes, theoretically of more federal character that, however, were refused in the referendum of 2006. The most relevant changes were the following ones: the configuration of the Senate according to a federal structure of the State; the organization of the competences granted attributions on the subject of health, school teaching and regional and local administrative police to the new Regions; a substantial modification of the relations between the Parliament and the Government to which it has given impulse to the Italian doctrine to consider it the form of government that with that it was modified. And other modifications that were suggested in the frustrated reform were: the deletion of the popular legislative initiative, the recognition of the independent administrative authorities and the defense of the local autonomy. 